This document is confidential and is proprietary to the American Chemical Society and its authors. Do not copy or disclose without written permission. If you have received this item in error, notify the sender and delete all copies.

\title{
Raman imaging reveals accumulation of hemoproteins in plaques from Alzheimer's diseased tissues
}

\begin{tabular}{|r|l|}
\hline Journal: & ACS Chemical Neuroscience \\
\hline Manuscript ID & cn-2021-00289w.R2 \\
\hline Manuscript Type: & Article \\
\hline Complete List of Authors: & $\begin{array}{l}\text { EL KHOURY, Youssef; Universite de Strasbourg Faculte de Chimie, } \\
\text { Schirer, Alicia; Universite de Strasbourg, Chemistry, UMR 7140 } \\
\text { Patte-Mensah, Christine; Université de Strasbourg, Inserm U1119 } \\
\text { KLEIN, Christian; Universite de Strasbourg, U1119 } \\
\text { Meyer, Laurence; Universite de Strasbourg, U1119 } \\
\text { Rataj-Baniowska, Monika; Universite de Strasbourg, U1119 } \\
\text { Bernad, Sophie; Laboratoire de Chimie Physique, CNRS UMR8000, } \\
\text { Moss, David; KIT, ANKA } \\
\text { Lecomte, Sophie; CBMN/ CNRS, } \\
\text { Mensah Nyagan, Ayikoe Guy; Universite de Strasbourg, U1119 } \\
\text { Hellwig, Petra; Universite de Strasbourg, Chemistry, UMR 7140 }\end{array}$ \\
\hline
\end{tabular}

\section{SCHOLARONE \\ Manuscripts}




\section{INTRODUCTION}

Alzheimer's disease (AD) is the most common neurodegenerative disorder and cause of dementia. The disease is patho-physiologically characterized by aggregated amyloid-beta $(\mathrm{A} \beta)$, neurofibrillary tangles composed of aggregated hyperphosphorylated tau protein and neuronal loss. There is cumulative evidence that oxidative stress plays a key role in the pathogenesis of various neurodegenerative disorders including AD. ${ }^{1-2}$ For instance, the level of heme oxygenase, an enzyme that catalyzes the subsequent degradation of free heme to carbon monoxide, was found to be increased in senile plaques ${ }^{3-4}$ and an abnormal level of free hemes was suggested to increase the production of toxic Reactive Oxygen Species (ROS) and reactive nitrogen species. Since then, interest in heme-A $\beta$ complexes capable of generating toxic ROS has been growing. ${ }^{5-13}$ Importantly,

hemes that are overproduced inside the brain cells of AD patients ${ }^{5}$ have to reach the extra-cellular domain to bind $\mathrm{A} \beta$ peptides. These free hemes (i.e. not bound to the scaffold of a hemoprotein) may be escaping apo-proteins and other heme binding biomolecules and this process will depend on the transport and delivery. ${ }^{14-15}$ Alternatively, free hemes can arrive to the outer side of the membrane as hemes bound to the scaffold of hemoproteins such as hemoglobin $(\mathrm{Hb})$ and neuroglobin $(\mathrm{Ngb})$. This is in line with the increased the levels of hemoglobin $(\mathrm{Hb})^{16-17}$ and neuroglobin $(\mathrm{Ngb})^{18}$ in the brain of $\mathrm{AD}$ patients, found colocalized with $\mathrm{A} \beta$ plaques. Thus, free type- $a^{5,19}$ and type- $b^{5}$ hemes extracted from the brain of $\mathrm{AD}$ patients can be the result of the overexpression of hemes inside the cells or the accumulation of type- $a$ and type- $b$ hemoproteins. It should be noted that previously used heme extraction methods ${ }^{5,19}$ allow the extraction of labile hemes bound to hemoproteins but not the covalently-attached type- $c$ heme 5,19 such as in cytochrome $c$ (cyt $c$ ) and information on the role of these type of hemoproteins is missing This motivated us to characterize the heme- $\mathrm{A} \beta$ complex within the $\mathrm{AD}$ plaques by means of infrared and Raman microspectroscopies. We used the former to gain information about the conformation of proteins through the socalled amide I band between 1700 and $1600 \mathrm{~cm}^{-1}$. This signal is sensitive to the secondary structure of proteins up to the point of differentiating parallel and antiparallel $\beta$-sheets. ${ }^{20}$ The latter helps is a highly complementary technique to infrared imaging. We used it for detecting hemes through excitation at $532 \mathrm{~nm}$, which is resonant with the $\alpha$ band of hemes.

\section{MATERIALS AND METHODS}


Behavioral characterization of AD transgenic mice and murine tissue preparation. The procedures involving animals and their care were conducted in compliance with a European Communities Council Directive (86/609/EEC) and under the supervision of authorized investigators. The protocols were reviewed and approved by the Alsace Head Office of the French Department of Veterinary and Public Health Guide for the Care and Use of Laboratory Animals. We used female APPSWE hemizygote mice [B6, SJL-Tg (APPSWE) $2576 \mathrm{Kha}$, tested for heterozygous RD1, Taconic Europe, Denmark]. These Tg2576 mice, which carry a transgene coding for the 695-amino acid isoform of human Alzheimer's beta-amyloid precursor protein, are well characterized as developing $\mathrm{A} \beta$ plaques and progressive memory deficits with age, making them suitable for the investigation of the relationship between $\mathrm{A} \beta$ accumulation/degradation and cognitive performance. ${ }^{21-23}$ We obtained the Tg2576 mice and their wild-type counterparts at the age of 6 months, and after 4 weeks of adaptation to our local animal facilities they were submitted to monthly behavioral analyses (from month 6 to 18) using the spatial novelty task to assess their cognitive performance. This task is based on the spontaneous tendency of mice to explore preferentially those objects which have been displaced within a familiar arrangement of objects. $\operatorname{Tg} 2576$ mice are deeply impaired in this task, independently of the rd mutation. ${ }^{24-25}$

The mean recognition index (RI in \% + SEM: standard error of the mean) calculated according to the formula: $[\mathrm{RI}=$ (exploration time of the displaced object / total time exploring the displaced and non-displaced objects) *100], during the first 5 minutes of the retention trial is shown in Figure S1 (See Supporting information). At the age of 6 months, all groups detected spatial novelty. At 12 or 18 months, Tg2576 mice were deeply impaired in the task: ${ }^{*} \mathrm{p}<0.05$ compared to the wild-type mice (Student's $\mathrm{t}$ test).

After the behavioral characterization, 18 months old $\operatorname{Tg} 2576$ and wild-type mice with severe cognitive deficit were killed, decapitated, and their brains were removed and rapidly transferred to an optimal cutting temperature medium and frozen by immersion in isopentane (cooled at $-40{ }^{\circ} \mathrm{C}$ ). Cryo-sections (10 $\mu \mathrm{m}$ thick) of frozen murine brains were made with a Reichert-Jung, LEICA instrument and mounted on $\mathrm{CaF}_{2}$ or $\mathrm{BaF}_{2}$ windows for Raman and infrared measurements, respectively. In total, $6 \mathrm{Tg} 2576$ and 6 wildtype mice were included in this study.

Labeling with thioflavin $S$ (Figure S2) as described by Sun, A. et al. ${ }^{26}$ and measurement with fluorescence was performed to confirm that the examined changes in the tissue correspond to plaques (Figure S3).

Human tissue preparation. The human brain tissues were a kind gift from the biological resources platform of the "Hôpital de la Pitié-Salpétrière" Paris, France. $30 \mu \mathrm{m}$ thick cryo-sections of the hippocampus were deposited on $\mathrm{CaF}_{2}$ or $\mathrm{BaF}_{2}$ windows for Raman and infrared measurements, respectively. Three hippocampi samples of $\mathrm{AD}$ deceased patients and one sample of a non-AD deceased patient were included in this study. The details of the human pathologies are shown in Table S1 (Supporting information). Plaques were identified in the tissue first by inspection with the microscope attached to the infrared and Raman instrument respectively (see below). Figure S4 shows the thioflavin $S$ staining of the hippocampus of an AD patient.

Preparation of commercial samples. Cyt $c$ from horse heart and $\mathrm{Hb}$ from equine heart, and hemin were purchased from SigmaAldrich and used without further purification. Human Ngb was purified as described in reference ${ }^{27}$. The $\mathrm{A} \beta 42 \mathrm{HCl}$ salt was purchased from rpeptide as lyophilized powder and used without further purification. The preparation of the hemin- $\mathrm{A} \beta 42$ complex was carried by dissolving hemin in $0.1 \mathrm{M} \mathrm{NaOH}$ and the $\mathrm{A} \beta 42$ in a phosphate buffer at $\mathrm{pH}$ 7.0. The $\mathrm{pH}$ of the hemin solution was brought down progressively to around $\mathrm{pH} 7$ to avoid aggregation. A 1:1 ratio hemin- $\mathrm{A} \beta 42$ solution was then prepared, and the formation of the $\sim 1: 1$ ratio complex was verified by following the modification of the Soret band in UV-Vis spectral range. ${ }^{6}$

For Raman spectroscopy, the different hemoproteins were dissolved in water at a concentration of about $2 \mathrm{mM}$. Excess of sodium dithionite was added in diluted protein samples to obtain the reduced forms. Note that the reduction of the heme samples was necessary to compare with the tissue samples that exhibit a typical reduced heme signature, probably photo-induced by the used laser (see below).

\section{Spectroscopy}

Optical microscopy: The optical microscopy image was obtained with a Leica DMR-X microscope and a Nikon Coolpix 995 camera in phase contrast mode.

Infrared microspectroscopy: Synchrotron FTIR microspectroscopy was performed at the beamline IR2 of the ANKA synchrotron facility (KIT, Karlsruhe, Germany) on an IRscope II infrared microscope (Bruker Optics, Germany). Infrared spectra were recorded using a $36 \mathrm{x}$ objective in transmission mode in the 700-4500 $\mathrm{cm}^{-1}$ spectral range with a spectral resolution of 4 $\mathrm{cm}^{-1}, 128$ co-added scans, $12.5 \mu \mathrm{m}$ aperture dimension and a step size of $4.16 \mu \mathrm{m}$. A background spectrum was collected from a clean $\mathrm{BaF}_{2}$ window after every 10 spectra. FTIR spectra and maps were analyzed using Cytospec v 2.00.01.

Raman spectroscopy: Raman spectroscopy was performed on a WITec Alpha300RS confocal Raman microscope using a $532 \mathrm{~nm}$ laser with a resolution of $2-3 \mathrm{~cm}^{-1}$ and with 600 lines $/ \mathrm{mm}$. Raman spectra of mice tissue samples were recorded using a 20x/NA 0.4 objective in the $0-3800 \mathrm{~cm}^{-1}$ spectral range with an integration time of $0.05 \mathrm{~s}$. The human samples were studied with the same microscope using a 50x/NA 0.75 objective in the $0-3800 \mathrm{~cm}^{-1}$ spectral range with an integration time of $1 \mathrm{~s}$. A spectrum was recorded every $0.5 \mu \mathrm{m}$ along the $\mathrm{x}$ and $\mathrm{y}$ directions. Raman spectra of model samples were recorded using a 50x/NA 0.75 objective in the $0-3800 \mathrm{~cm}^{-1}$ spectral range with an integration time of $10 \mathrm{~s}$ using $532 \mathrm{~nm}$ (WITec Alpha300RS Raman microscope). The baseline of the Raman spectra of the isolated cyt $c$ and Ngb were corrected due to the high fluorescence. The resolution of the later instrument was 1200 lines/mm, corresponding to about $1 \mathrm{~cm}^{-1}$. Raman spectra and maps were analyzed using WITec or the Renishaw software, respectively.

\section{RESULTS AND DISCUSSIONS}

Infrared microspectroscopy. The amide I and amide II signals measured for diseased and normal mice and human brain tissues are shown in Figure 1A and 1C, respectively. These amide signals correspond to the $\mathrm{C}=\mathrm{O}$ and the coupled $\mathrm{CN} / \mathrm{NH}$ vibrational modes of the protein backbone. The position of the $\mathrm{C}=\mathrm{O}$ vibrational mode corresponds to a specific secondary structure. ${ }^{20} \mathrm{~A}$ transition of the amide I peak from $1662 \mathrm{~cm}^{-1}$ (black line, normal mice tissue) to $1630 \mathrm{~cm}^{-1}$ (red line, diseased tissue) is seen. The shift corresponds to the expected accumulation of peptides and proteins organized in parallel $\beta$-sheet type structures. ${ }^{28}$ In $\mathrm{AD}$, this accumulation is related to the aggregation of $\mathrm{A} \beta .^{29}$ The map obtained by infrared microscopy (Figure 1B) shows the intensity distribution of the $1630 \mathrm{~cm}^{-1}$ signal, revealing the strong concentration of parallel $\beta$ sheet type structures in the core of the plaque (bright color in the map) and its absence in the surroundings (dark color). Moreover, the downshift of the amide II from 1550 to $1542 \mathrm{~cm}^{1}$ can be associated with the increase $\beta$-sheet content, ${ }^{30}$ i.e. $\mathrm{A} \beta$ aggregates. The signal at $1747 \mathrm{~cm}^{-1}$ observed in panel A can be assigned to the 
ester $\mathrm{C}=\mathrm{O}$ stretching vibration of phospholipids. ${ }^{31-33}$ In line with previous studies, the absence of the phospholipids signals in the plaque core suggests that phospholipids form a ring around the aggregated $\mathrm{A} \beta .^{34-36}$

It should be noted that the plaques were identified by staining with thioflavin $S$ (Figure S2). The microscopic image of a typical sample of the hippocampus from 18 months old Tg2576 mice is shown in Figure S3. All aggregates studied here have been found to be clearly distinguishable from the normal tissue and to show highly reproducible spectral properties (Figure S5). Their size is typically $10 \mu \mathrm{m}$ for 18 months diseased mice.

In analogy to the mice sample, a human $\mathrm{AD}$ sample was examined by infrared microspectroscopy. Figure 1C shows the amide I and II modes obtained from human AD brain tissue. The spectrum (black trace) recorded away from the senile plaque shows a maximum at $1655 \mathrm{~cm}^{-1}$ and a shoulder appears at $1634 \mathrm{~cm}^{-1}$ in the spectrum of the plaques (red trace). This shoulder can be assigned to the accumulation of aggregated $\mathrm{A} \beta$. Clearly the spectra of healthy and diseased parts of the human sample differ from the murine one especially regarding the sharp signal appearing in the murine sample at $1630 \mathrm{~cm}^{-1}$ whereas the human sample shows a shoulder at $1634 \mathrm{~cm}^{-1}$. The observed difference between the murine and human samples is most likely caused by the difference in composition of tissue between humans and mice ${ }^{37-38}$ as well as by the thickness of the sample; the human sample is 3 times thicker than the murine one, hence it is more difficult to observe the markers of the senile plaques against a thicker healthy tissue in the background. Figure 1D shows the infrared map of the human plaque obtained at $1634 \mathrm{~cm}^{-1}$. A higher intensity at $1634 \mathrm{~cm}^{-1}$ is found in the core of the plaque, in line with the data obtained for the murine sample.

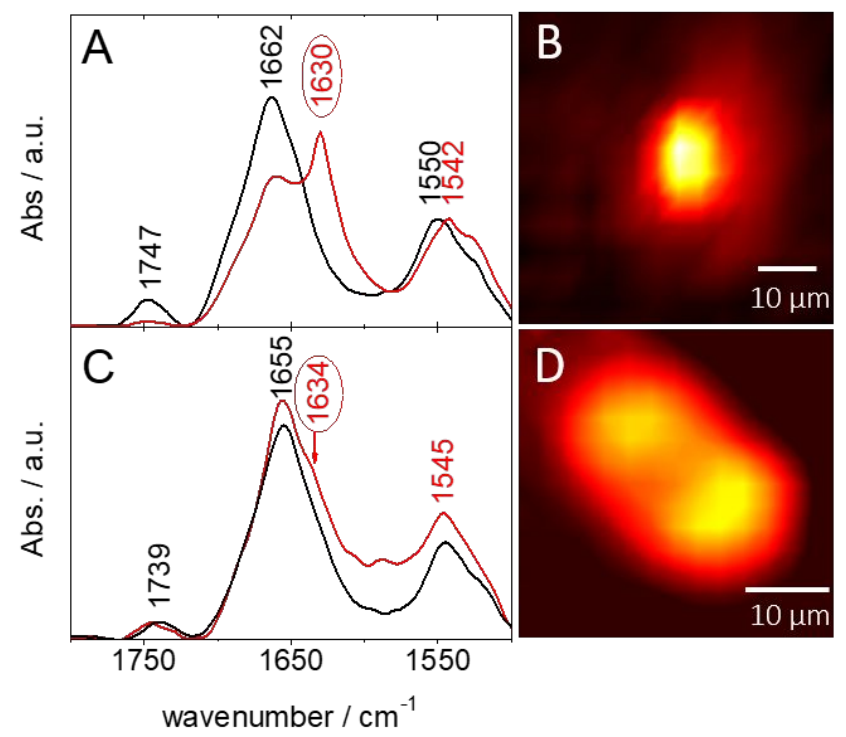

Figure 1. Infrared spectra of murine (Panel A) and human (Panel C) brain tissue away from the plaque (black line) and on the plaque tissue (red line) in the $1800-1500 \mathrm{~cm}^{-1}$ spectral range. The infrared maps of the murine (Panel B) and human (Panel D) obtained on the basis of the intensity distribution of the specific band (circled wavenumber). Bright color corresponds to a high intensity and dark color to a low intensity. The FTIR spectra were obtained at ANKA IR beamline (For details see materials and methods).

\section{Raman microspectroscopy}

Figure 2A shows the Raman spectra obtained in the spectral range 1800 to $600 \mathrm{~cm}^{-1}$ for the murine senile plaque (red) in comparison to the healthy tissue (black). Several sharp and strongly enhanced signals can be identified in the spectrum. For instance, the signals at 1587, 1366, 1132 and $754 \mathrm{~cm}^{-1}$ are all assigned to hemes modes. ${ }^{39}$ Figure 1C displays the relative intensity distribution of the signal observed at $1587 \mathrm{~cm}^{-1}$ (assigned to the antisymmetric $v(\mathrm{C}=\mathrm{C})$ vibration of the heme skeleton (i.e. $v 2)){ }^{40}$ The intensity of this signal is about $3.3 \pm 1.3$ higher in the plaque relative to the healthy tissue as assessed from eight different samples. Noticeably, a quite homogeneous distribution of the contribution is found in the plaque, with a high intensity found in the entire plaque and low signal intensity in the surrounding tissue. Figure 2D shows the analysis of three different samples from patients who suffered from AD as well as a control sample taken from non-AD person (See Table S1). Several of the heme marker bands identified in the murine samples can be found also in the human tissue. It is noted that the signals are highly similar between the tissues of the different patients, confirming their accumulation in the plaque of $\mathrm{AD}$ patients. The mapping of the tissue at 1590 $\mathrm{cm}^{-1}$ reveals the distribution of hemoproteins in the entire plaque.

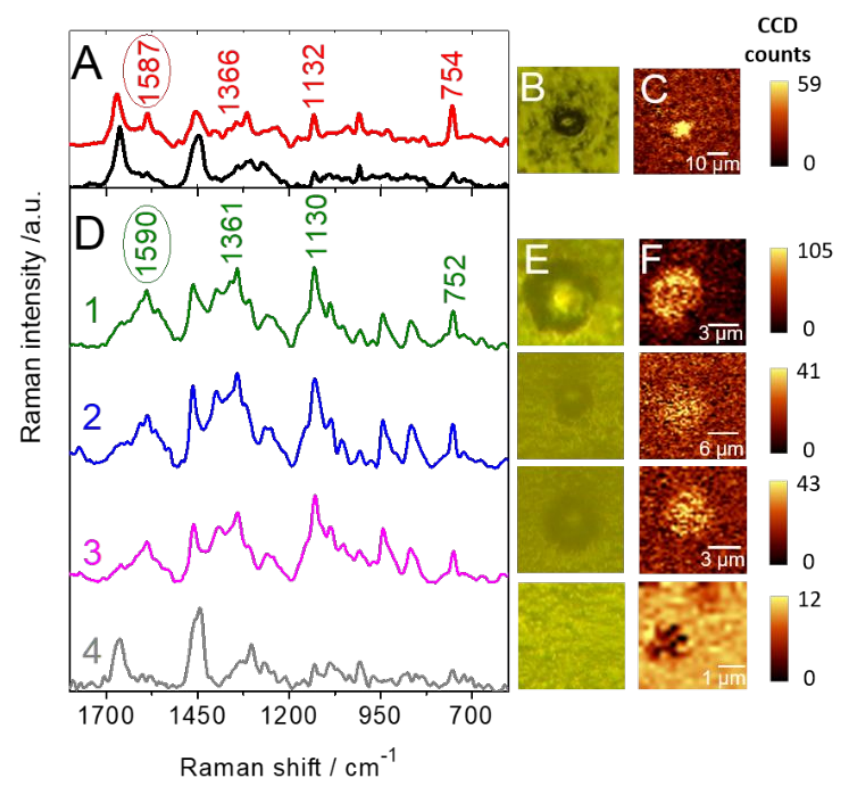

Figure 2. Raman mapping of the murine and human samples. Panel A shows the average spectra of the murine plaques (red trace) and its surrounding (black trace). Panels B and $\mathrm{C}$ show respectively the corresponding white light and Raman image at $1587 \mathrm{~cm}^{-1}$. Panel D shows the average spectra of human plaques. Traces 1-3 correspond to three human AD samples and trace 4 corresponds to a non-AD control as described in Table S1 of the Supporting information. Panels E and F show respectively the corresponding white light and Raman image at $1590 \mathrm{~cm}^{-1}$. The Raman images were obtained with an excitation at $532 \mathrm{~nm}$; NA $0.4: 11 \mathrm{~mW}$ at $2-3 \mathrm{~cm}^{-1}$ resolution. The spectra are off-set for clarity. The bright color corresponds to a high intensity and dark color to a low intensity.

The Raman data in Figure 3 show the direct comparison of the tissues (human and murine) with reduced $\mathrm{Hb}$, reduced $\mathrm{Ngb}$, reduced cyt $c$, as well as a hemin-A $\beta 42$ complex. Resonance Raman spectroscopy is specific for the exact type of ligation, spin and redox state as well as the environment of the porphyrin ring and can thus be used to identify and distinguish the heme type. ${ }^{39,41}$ The signal found at $1366 \mathrm{~cm}^{-1}$ in the spectrum of the murine plaque and at $1362 \mathrm{~cm}^{-1}$ in the spectrum of the human plaque is a marker 
of reduced heme (or hemoprotein). ${ }^{39}$ The characteristic signals that may be arising from the hemoproteins (or free hemes) in the tissue are traced with vertical lines. Several signals detected from murine and human plaques may be correlated with modes of a low-spin 6coordinated heme. ${ }^{41}$ In particular the $v 2$ mode at $1587 \mathrm{~cm}^{-1}$ is a marker for the spin state of the heme where the hemoprotein is in the low-spin state. The $v 3$ mode, observed at $1501 \mathrm{~cm}^{-1}$ in the spectrum of the murine sample and at $1505 \mathrm{~cm}^{-1}$ in the spectrum of the human sample indicate that the heme is hexa-coordinated. The wavenumber of the heme marker bands found in the various samples are shown in Table 1. Clearly, type- $b$ (free heme, $\mathrm{Hb}$ and $\mathrm{Ngb}$ ) and type- $c$ hemes can be responsible for the enhanced signals in the plaques since their wavenumbers match the ones found in the tissue samples. heme $a$ absorbs between 603 and $611 \mathrm{~nm}^{42}$ it is thus not resonant with the laser (i.e. $532 \mathrm{~nm}$ ) used here. Therefore, even if heme $a$ is present in the brain tissue samples, its contribution can be overshadowed by the contribution of the resonant type- $b$ and type- $c$ hemes. Thus, type- $a$ heme is not discussed.

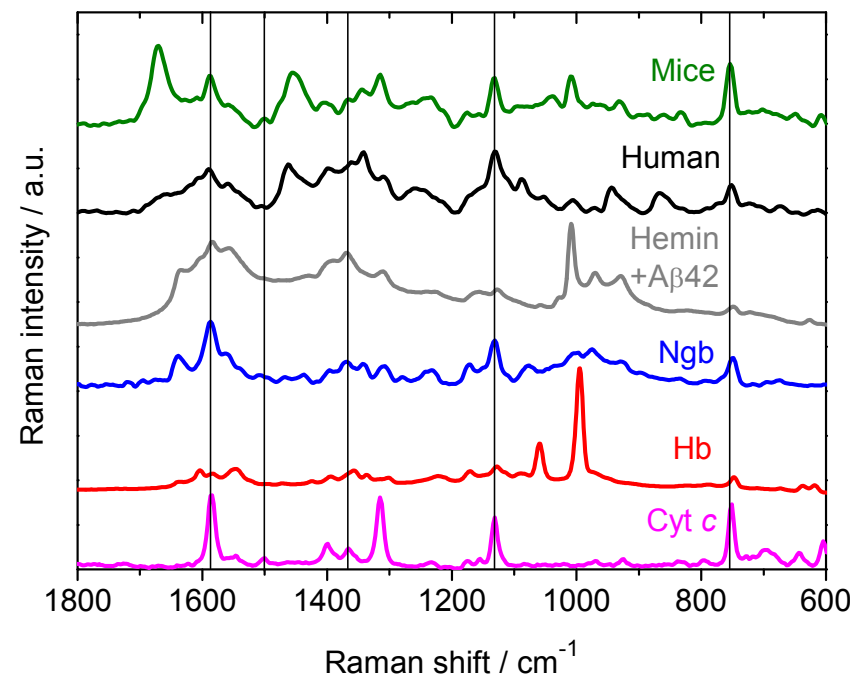

Figure 3. Comparison of Raman spectra of murine plaque (green line), human plaque (black line), hemin-amyloid beta 42 complex (grey line), reduced neuroglobin (blue line), reduced hemoglobin (red line) and reduced cytochrome $c$ (magenta line). The spectra are obtained with excitation at $532 \mathrm{~nm}$, NA 0.4: $11 \mathrm{~mW}$, at $2-3 \mathrm{~cm}^{-1}$ resolution. The vertical lines highlighted the frequency of characteristic bands from the murine plaques to facilitate the comparison to the other spectra.

Table 1. Raman shift in $\mathrm{cm}^{-1}$ of the heme modes in the different samples.

\begin{tabular}{|cccccc|}
\hline $\begin{array}{c}\text { Assignmen } \\
\mathrm{t}^{39-41}\end{array}$ & $v 2$ & $v 3$ & $v 4$ & $v 14$ & $v 15$ \\
\hline \hline \multicolumn{7}{c|}{ Brain tissue } \\
\hline \hline Mice & 1587 & 1501 & 1366 & 1132 & 754 \\
Human & 1590 & 1505 & 1362 & 1130 & 752 \\
\hline \hline \multicolumn{7}{c}{ Type $b$ heme } \\
\hline \hline Hemin & 1584 & 1501 & 1370 & 1128 & 749 \\
N $\beta 42$ & 1587 & 1500 & 1369 & 1132 & 749 \\
$\mathrm{Hb}$ & 1584 & 1496 & 1356 & 1128 & 748 \\
\hline \hline
\end{tabular}

\begin{tabular}{|llllll|}
\hline \hline \multicolumn{6}{|c|}{ Type $c$ heme } \\
\hline \hline Cyt c & 1586 & 1500 & 1366 & 1131 & 751 \\
\hline
\end{tabular}

In line with previous results, $\mathrm{Hb}^{16-17}$ can be responsible for the observed Raman marker bands. The potential accumulation of cyt $c$ in the senile plaques could result from the release of cyt $c$ due to apoptosis $^{43}$ and could act as a signaling molecule for brain microglia leading to regulate the immune response. ${ }^{44} \mathrm{Ngb}$ was found upregulated in $\mathrm{AD}$ brains and previously detected accumulating in plaques. ${ }^{18}$ Some in vitro studies and cell culture experiments suggest that neuroglobin may detoxify ROS or nitric oxide and when accumulated in the tissue it may be present as a reaction to the cell's death and the increased ROS produced. Interestingly $\mathrm{Ngb}$ was suggested to protect neurons from $\mathrm{A} \beta$ induced neurotoxicity as Ngb overexpressing transgenic mice were resistant to the toxic effects. ${ }^{45}$ Thus, it would not be surprising to find $\mathrm{Ngb}$ in the senile plaques. Interestingly cyt $c$ is a binding partner for neuroglobin ${ }^{46-47}$ and it was shown that a fast electron transfer between the heme iron centers in ferrous Ngb and ferric cyt $c$ takes place, proposing a fast association of $\mathrm{Ngb}$ to pro-apoptic cyt c. . $^{48-49}$

Consequently, important questions in $\mathrm{AD}$ research field rise: i) why do hemes and/or hemoproteins accumulate in $\mathrm{A} \beta$ plaques and not in the surrounding tissue? Is this a result of the aggregation cascade? ii) does this accumulation have a beneficial role by enhancing the brain immune system to clear the plaques? or iii) does it have a damaging role in accelerating the plaques formation by increasing the production of ROS?

\section{CONCLUSIONS}

In this study we investigated the vibrational signature of $A D$ plaques from mice and human samples. FTIR imaging highlighted the presence of $\beta$-sheet aggregates of $\mathrm{A} \beta$ peptides in the senile plaques of both murine and human samples. Raman imaging at 532 $\mathrm{nm}$ confirms the accumulation of heme in the plaques but the similarity of Raman signature of free hemin bound to $\mathrm{A} \beta-42$ and type- $b$ and type- $c$ hemoproteins does not allow ruling out one or the other hemoprotein. Therefore, free hemes or $\mathrm{Hb}, \mathrm{Ngb}$ and cyt $c$ hemoproteins could be accumulating in the $\mathrm{A} \beta$ plaques. Due to the suggested implication of the heme in AD pathophysiology, we believe that it is necessary to further investigate the type of the heme to provide solid proof on the accumulation of either type of hemoproteins in $\mathrm{AD}$ plaques and to shed more light on the binding mode of $\mathrm{A} \beta$ to the heme moieties.

\section{ASSOCIATED CONTENT}

\section{Supporting Information}

The Supporting Information is available free of charge on the ACS Publications website. Mice behavioral analysis, the Braak stage of the human subjects, plaque thioflavin $S$ staining and additional Raman imaging data of mice plaques (PDF).

\section{AUTHOR INFORMATION}

\section{Corresponding Author}

Sophie Lecomte - Chimie Biologie des Membranes et Nanoobjets, UMR 5248, Université de Bordeaux-CNRS. 14 Allée Geoffroy St. Hilaire, 33600 Pessac, France.

E-mail: s.lecomte@cbmn.u-bordeaux.fr

Ayikoe-Guy Mensah-Nyagan - Biopathologie de la Myéline, Neuroprotection et Stratégies Thérapeutiques, INSERM U1119, 
Fédération de Médecine Translationnelle de Strasbourg (FMTS) ; Université de Strasbourg. 1 rue Eugène Boeckel, 67000 Strasbourg, France. E-mail: gmensah@unistra.fr

Petra Hellwig - Laboratoire de bioélectrochimie et spectroscopie. UMR 7140, chimie de la matière complexe ; Université de Strasbourg-CNRS. ; 4, Rue Blaise Pascal 67081 Strasbourg, France. E-mail: hellwig@unistra.fr

\section{Present Addresses}

(Word Style "Section_Content"). †If an author's address is different than the one given in the affiliation line, this information may be included here.

\section{Author Contributions}

Youssef El Khoury and Alicia Schirer performed the spectroscopy experiments, prepared the figures and prepared the manuscript, Christine Patte-Mensah, Christian Klein, Laurence Meyer and Monika Rataj-Baniowska have been in charge of the mice and the preparation of the tissues, Sophie Bernad, prepared the Neuroglobin samples, David Moss, supervised the IR experiments at the synchrotron in Karlsruhe and supported data analysis, Sophie Lecomte, supervised the Raman imaging and supported the data analysis, Ayikoe-Guy Mensah-Nyagan, supervised the mice experiments and supported data analysis and Petra Hellwig, coordinated the collaboration and supported the preparation of the manuscript. All senior authors raised funding All authors reviewed the manuscript.

\section{Note}

The authors declare no competing financial interests.

\section{ACKNOWLEDGMENT}

We thank Etienne Harte and Sandrine Villette (CBMN, CNRSUniversity of Bordeaux), Valérie Derrien (LCP, CNRSUniversity Paris Sud) for technical assistance and Martin Brinkmann (University of Strasbourg - CNRS) for the OM image. We are grateful to Neuro-CEB (Hôpital de la Pitié-Salpétrière, Paris France) for the kind gift of the human brain tissue samples. Financial support from the University of Strasbourg, the CNRS, the icFRC and the INSERM is gratefully acknowledged.

\section{ABBREVIATIONS}

$\mathrm{A} \beta$, amyloid beta; $\mathrm{AD}$, Alzheimer's disease; Cyt $c$, Cytochrome $c$; FTIR, Fourier transform infrared; Hb, Hemoglobin; Ngb, Neuroglobin; ROS, Reactive Oxygen Species;

\section{REFERENCES}

1. LaFerla, F. M.; Oddo, S., Alzheimer's disease: Abeta, tau and synaptic dysfunction. Trends Mol. Med. 2005, 11 (4), 170-6.

$2 . \quad$ Zhao, Y.; Zhao, B., Oxidative stress and the pathogenesis of Alzheimer's disease. Oxid. Med. Cell. Longev. 2013, 2013, 316523.

3. Schipper, H. M.; Cisse, S.; Stopa, E. G., Expression of heme oxygenase- 1 in the senescent and Alzheimer-diseased brain. Ann. Neurol. 1995, 37 (6), 758-68.

$4 . \quad$ Smith, M. A.; Kutty, R. K.; Richey, P. L.; Yan, S. D.; Stern, D.; Chader, G. J.; Wiggert, B.; Petersen, R. B.; Perry, G., Heme oxygenase- 1 is associated with the neurofibrillary pathology of Alzheimer's disease. Am. J. Pathol. 1994, 145 (1), $42-7$.

5. Atamna, H.; Frey, W. H., 2nd, A role for heme in Alzheimer's disease: heme binds amyloid beta and has altered metabolism. Proc. Natl. Acad. Sci. U. S. A. 2004, 101 (30), 11153-8.

6. Atamna, H.; Boyle, K., Amyloid-beta peptide binds with heme to form a peroxidase: relationship to the cytopathologies of Alzheimer's disease. Proc. Natl. Acad. Sci. U. S. A. 2006, 103 (9), 3381-6. 7. Atamna, H.; Frey, W. H., 2nd; Ko, N., Human and rodent amyloid-beta peptides differentially bind heme: relevance to the human susceptibility to Alzheimer's disease. Arch. Biochem. Biophys. 2009, 487 (1), 59-65.

$8 . \quad$ Ghosh, C.; Seal, M.; Mukherjee, S.; Ghosh Dey, S., Alzheimer's Disease: A Heme-Abeta Perspective. Acc. Chem. Res. 2015, 48 (9), 255664.

9. Pramanik, D.; Ghosh, C.; Dey, S. G., Heme-Cu bound abeta peptides: spectroscopic characterization, reactivity, and relevance to Alzheimer's disease. J. Am. Chem. Soc. 2011, 133 (39), 15545-52.

10. Yuan, C.; Yi, L.; Yang, Z.; Deng, Q.; Huang, Y.; Li, H.; Gao, Z., Amyloid beta-heme peroxidase promoted protein nitrotyrosination: relevance to widespread protein nitration in Alzheimer's disease. $J$. Biol. Inorg. Chem. 2012, 17 (2), 197-207.

11. Pramanik, D.; Ghosh, C.; Mukherjee, S.; Dey, S. G., Interaction of amyloid $\beta$ peptides with redox active heme cofactor: Relevance to Alzheimer's disease. Coord. Chem. Rev. 2013, 257 (1), 81-92.

12. Seal, M.; Mukherjee, S.; Pramanik, D.; Mittra, K.; Dey, A.; Dey, S. G., Analogues of oxy-heme Abeta: reactive intermediates relevant to Alzheimer's disease. Chem. Commun. 2013, 49 (11), 1091-3.

13. Roy, M.; Pal, I.; Nath, A. K.; Dey, S. G., Peroxidase activity of heme bound amyloid $\beta$ peptides associated with Alzheimer's disease. Chem. Commun. 2020, 56 (33), 4505-4518.

14. Donegan, R. K.; Moore, C. M.; Hanna, D. A.; Reddi, A. R., Handling heme: The mechanisms underlying the movement of heme within and between cells. Free Radic. Biol. Med. 2019, 133, 88-100.

15. Chambers, I. G.; Willoughby, M. M.; Hamza, I.; Reddi, A. R., One ring to bring them all and in the darkness bind them: The trafficking of heme without deliverers. Biochim. Biophys. Acta, Mol. Cell Res. 2021, 1868 (1), 118881.

16. Wu, C. W.; Liao, P. C.; Yu, L.; Wang, S. T.; Chen, S. T.; Wu, C. M.; Kuo, Y. M., Hemoglobin promotes Abeta oligomer formation and localizes in neurons and amyloid deposits. Neurobiol. Dis. 2004, 17 (3), 367-77.

17. Chuang, J. Y.; Lee, C. W.; Shih, Y. H.; Yang, T. T.; Yu, L.; Kuo, Y. M., Interactions between Amyloid-beta and Hemoglobin: Implications for Amyloid Plaque Formation in Alzheimer's Disease. Plos One 2012, 7 (3).

18. Sun, F.; Mao, X. O.; Xie, L.; Greenberg, D. A.; Jin, K. L., Neuroglobin Protein is Upregulated in Alzheimer's Disease. J. Alzheimers Dis. 2013, 36 (4), 659-663.

19. Dwyer, B. E.; Stone, M. L.; Gorman, N.; Sinclair, P. R.; Perry, G.; Smith, M. A.; Zhu, X., Heme-a, the heme prosthetic group of cytochrome c oxidase, is increased in Alzheimer's disease. Neurosci. Lett. 2009, 461 (3), 302-5.

20. Goormaghtigh, E.; Cabiaux, V.; Ruysschaert, J. M., Determination of soluble and membrane protein structure by Fourier transform infrared spectroscopy. III. Secondary structures. Subcell. Biochem. 1994, 23, 405-50.

21. Hsiao, K.; Chapman, P.; Nilsen, S.; Eckman, C.; Harigaya, Y.; Younkin, S.; Yang, F.; Cole, G., Correlative memory deficits, Abeta elevation, and amyloid plaques in transgenic mice. Science 1996, 274 (5284), 99-102.

22. Westerman, M. A.; Cooper-Blacketer, D.; Mariash, A.; Kotilinek, L.; Kawarabayashi, T.; Younkin, L. H.; Carlson, G. A.; Younkin, S. G.; Ashe, K. H., The relationship between Abeta and memory in the $\operatorname{Tg} 2576$ mouse model of Alzheimer's disease. J. Neurosci. 2002, 22 (5), 1858-67.

23. Mawuenyega, K. G.; Sigurdson, W.; Ovod, V.; Munsell, L.; Kasten, T.; Morris, J. C.; Yarasheski, K. E.; Bateman, R. J., Decreased clearance of CNS beta-amyloid in Alzheimer's disease. Science 2010, 330 (6012), 1774.

24. Ognibene, E.; Middei, S.; Daniele, S.; Adriani, W.; Ghirardi, O.; Caprioli, A.; Laviola, G., Aspects of spatial memory and behavioral 
disinhibition in Tg2576 transgenic mice as a model of Alzheimer's disease. Behav. Brain. Res. 2005, 156 (2), 225-32.

$25 . \quad$ Yassine, N.; Lazaris, A.; Dorner-Ciossek, C.; Despres, 0.; Meyer, L.; Maitre, M.; Mensah-Nyagan, A. G.; Cassel, J. C.; Mathis, C., Detecting spatial memory deficits beyond blindness in tg2576 Alzheimer mice. Neurobiol. Aging 2013, 34 (3), 716-30.

26. Sun, A.; Nguyen, X. V.; Bing, G., Comparative analysis of an improved thioflavin-s stain, Gallyas silver stain, and immunohistochemistry for neurofibrillary tangle demonstration on the same sections. J. Histochem. Cytochem. 2002, 50 (4), 463-72.

27. Andre, E.; Derrien, V.; Sebban, P.; Assrir, N.; Lescop, E.; Bernad, S., Impact of A90P, F106L and H64V mutations on neuroglobin stability and ligand binding kinetics. J. Biol. Inorg. Chem. 2018.

$28 . \quad H e y s$, K. A.; Shore, R. F.; Pereira, M. G.; Martin, F. L., Levels of Organochlorine Pesticides Are Associated with Amyloid Aggregation in Apex Avian Brains. Environ. Sci. Technol. 2017, 51 (15), 8672-8681.

29. Hiramatsu, H.; Kitagawa, T., FT-IR approaches on amyloid fibril structure. Biochim. Biophys. Acta 2005, 1753 (1), 100-7.

30. Jackson, M.; Mantsch, H. H., The Use and Misuse of FTIR Spectroscopy in the Determination of Protein Structure. Crit. Rev. Biochem. Mol. Biol. 1995, 30 (2), 95-120.

31. Choo, L. P.; Wetzel, D. L.; Halliday, W. C.; Jackson, M.; LeVine, S. M.; Mantsch, H. H., In situ characterization of beta-amyloid in Alzheimer's diseased tissue by synchrotron Fourier transform infrared microspectroscopy. Biophys. J. 1996, 71 (4), 1672-9.

32. Rehman, I. u. M., Zanyar; Rehman, Shazza, Vibrational spectroscopy for tissue analysis. CRC Press: United States of America, 2013; p 319.

33. Miller, L. M.; Dumas, P., Chemical imaging of biological tissue with synchrotron infrared light. Biochim. Biophys. Acta 2006, 1758 (7), 846-57.

34. Cunha, R.; Lafeta, L.; Fonseca, E. A.; Barbosa, A.; RomanoSilva, M. A.; Vieira, R.; Jorio, A.; Malard, L. M., Nonlinear and vibrational microscopy for label-free characterization of amyloid- $\beta$ plaques in Alzheimer's disease model. Analyst 2021.

35. Palombo, F.; Tamagnini, F.; Jeynes, J. C. G.; Mattana, S.; Swift, I.; Nallala, J.; Hancock, J.; Brown, J. T.; Randall, A. D.; Stone, N., Detection of $A \beta$ plaque-associated astrogliosis in Alzheimer's disease brain by spectroscopic imaging and immunohistochemistry. Analyst 2018, 143 (4), 850-857.

36. Rohr, D.; Boon, B. D. C.; Schuler, M.; Kremer, K.; Hoozemans, J. J. M.; Bouwman, F. H.; El-Mashtoly, S. F.; Nabers, A. Grosserueschkamp, F.; Rozemuller, A. J. M.; Gerwert, K., Label-free vibrational imaging of different Abeta plaque types in Alzheimer's disease reveals sequential events in plaque development. Acta Neuropathol. Commun. 2020, 8 (1), 222.

37. Hodge, R. D.; Bakken, T. E.; Miller, J. A.; Smith, K. A.; Barkan, E. R.; Graybuck, L. T.; Close, J. L.; Long, B.; Johansen, N.; Penn, O.; Yao, Z.; Eggermont, J.; Hollt, T.; Levi, B. P.; Shehata, S. I.; Aevermann, B.; Beller, A.; Bertagnolli, D.; Brouner, K.; Casper, T.; Cobbs, C.; Dalley, R.; Dee, N.; Ding, S. L.; Ellenbogen, R. G.; Fong, O.; Garren, E.; Goldy, J.; Gwinn, R. P.; Hirschstein, D.; Keene, C. D.; Keshk, M.; Ko, A. L.; Lathia, K.; Mahfouz, A.; Maltzer, Z.; McGraw, M.; Nguyen, T. N.; Nyhus, J.; Ojemann, J. G.; Oldre, A.; Parry, S.; Reynolds, S.; Rimorin, C.; Shapovalova, N. V.;
Somasundaram, S.; Szafer, A.; Thomsen, E. R.; Tieu, M.; Quon, G.; Scheuermann, R. H.; Yuste, R.; Sunkin, S. M.; Lelieveldt, B.; Feng, D.; Ng, L.; Bernard, A.; Hawrylycz, M.; Phillips, J. W.; Tasic, B.; Zeng, H.; Jones, A. R.; Koch, C.; Lein, E. S., Conserved cell types with divergent features in human versus mouse cortex. Nature 2019, 573 (7772), 61-68.

38. Kalmbach, B. E.; Buchin, A.; Long, B.; Close, J.; Nandi, A.; Miller, J. A.; Bakken, T. E.; Hodge, R. D.; Chong, P.; de Frates, R.; Dai, K.; Maltzer, Z.; Nicovich, P. R.; Keene, C. D.; Silbergeld, D. L.; Gwinn, R. P.; Cobbs, C.; Ko, A. L.; Ojemann, J. G.; Koch, C.; Anastassiou, C. A.; Lein, E. S.; Ting, J. T., h-Channels Contribute to Divergent Intrinsic Membrane Properties of Supragranular Pyramidal Neurons in Human versus Mouse Cerebral Cortex. Neuron 2018, 100 (5), 1194-1208 e5.

$39 . \quad$ Spiro, T. G.; Strekas, T. C., Resonance Raman spectra of heme proteins. Effects of oxidation and spin state. J. Am. Chem. Soc. 1974, 96 (2), 338-45.

40. Hu, S.; Morris, I. K.; Singh, J. P.; Smith, K. M.; Spiro, T. G., Complete assignment of cytochrome c resonance Raman spectra via enzymic reconstitution with isotopically labeled hemes. J. Am. Chem. Soc. 1993, 115 (26), 12446-12458.

41. Loehr, T. M.; Loehr, J. S., Determination of oxidation and spin states of heme iron. Resonance Raman spectroscopy of cytochrome c, microperoxidase, and horseradish peroxidase. Biochem. Biophys. Res. Commun. 1973, 55 (1), 218-23.

42. Melin, F.; Hellwig, P., Redox Properties of the Membrane Proteins from the Respiratory Chain. Chem. Rev. 2020, 120 (18), 10244-10297.

43. Renz, A.; Berdel, W.E.; Kreuter, M.; Belka, C.; Schulze-Osthoff, K.; Los, M., Rapid extracellular release of cytochrome c is specific for apoptosis and marks cell death in vivo. Blood 2001, 98 (5), 1542-1548. 44. Gouveia, A.; Bajwa, E.; Klegeris, A., Extracellular cytochrome $\mathrm{c}$ as an intercellular signaling molecule regulating microglial functions. Biochim. Et Biophys. Acta Gen. Subj. 2017, 1861 (9), 2274-2281.

45. Khan, A. A.; Mao, X. O.; Banwait, S.; Jin, K.; Greenberg, D. A. Neuroglobin attenuates beta-amyloid neurotoxicity in vitro and transgenic Alzheimer phenotype in vivo. Proc. Natl. Acad. Sci. U. S. A. 2007, 104 (48), 19114-9.

46. Tiwari, P. B.; Astudillo, L.; Pham, K.; Wang, X.; He, J.; Bernad, S.; Derrien, V.; Sebban, P.; Miksovska, J.; Darici, Y., Characterization of molecular mechanism of neuroglobin binding to cytochrome c: A surface plasmon resonance and isothermal titration calorimetry study. Inorg. Chem. Commun. 2015, 62, 37-41.

47. Tiwari, P. B.; Chapagain, P. P.; Üren, A., Investigating molecular interactions between oxidized neuroglobin and cytochrome c. Sci. Rep. 2018, 8 (1), 10557.

48. Fago, A.; Mathews, A. J.; Moens, L.; Dewilde, S.; Brittain, T., The reaction of neuroglobin with potential redox protein partners cytochrome b5 and cytochrome c. FEBS Lett. 2006, 580 (20), 4884-8. 49. Fago, A.; Mathews, A. J.; Brittain, T., A role for neuroglobin: resetting the trigger level for apoptosis in neuronal and retinal cells. IUBMB Life 2008, 60 (6), 398-401. 


\section{SYNOPSIS TOC}

1
2

3

4

5

6

7

8

9

\section{hemoproteins in senile plaques}

Authors are required to submit a graphic entry for the Table of Contents (TOC) that, in conjunction with the manuscript title, should give the reader a representative idea of one of the following: A key structure, reaction, equation, concept, or theorem, etc., that is discussed in the manuscript. Consult the journal's Instructions for Authors for TOC graphic specifications. 
ACS Chemical Neuroscience

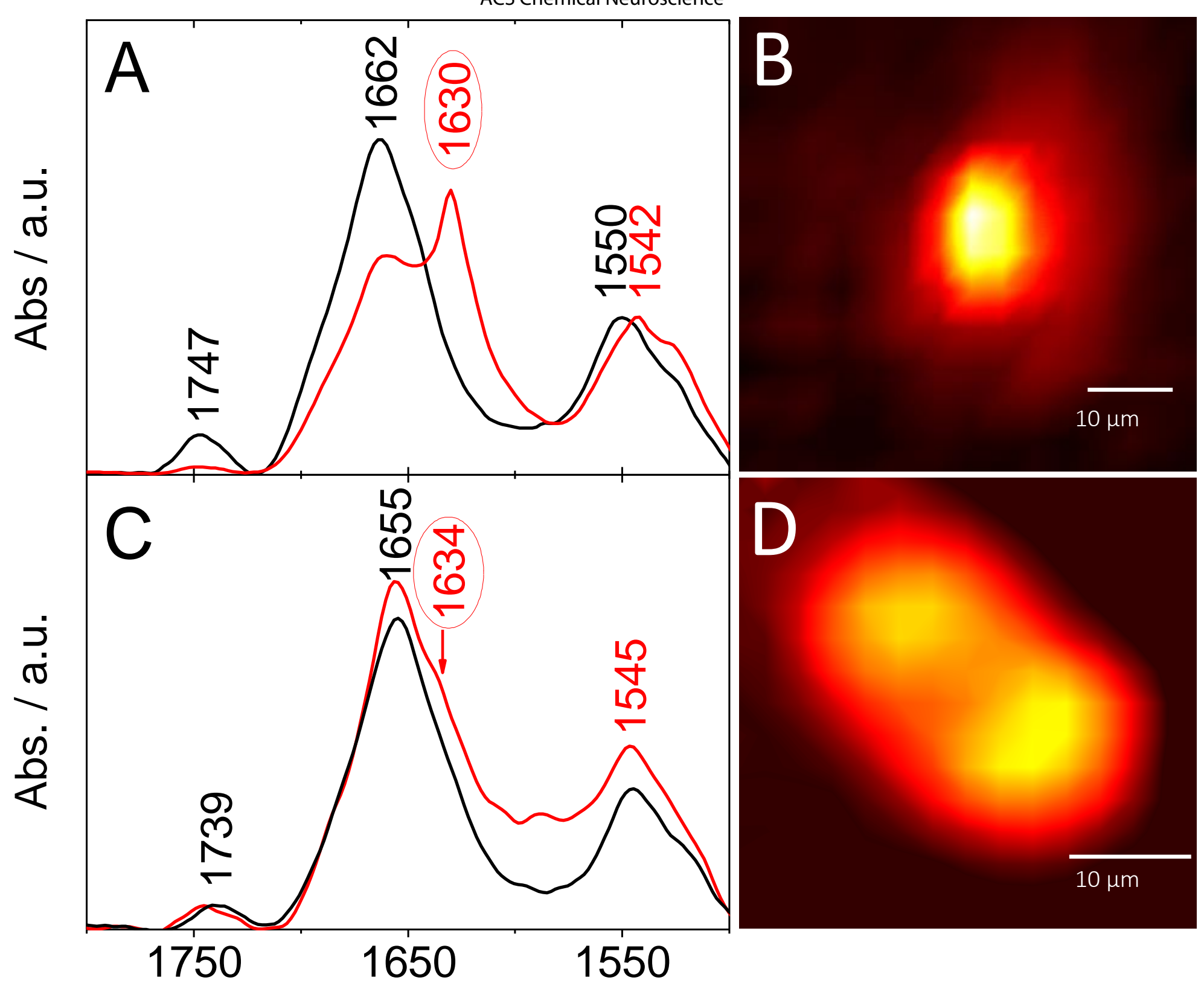

wavenumber ${ }^{\text {Acs Paragon } \text { Plus Environment }}$ 


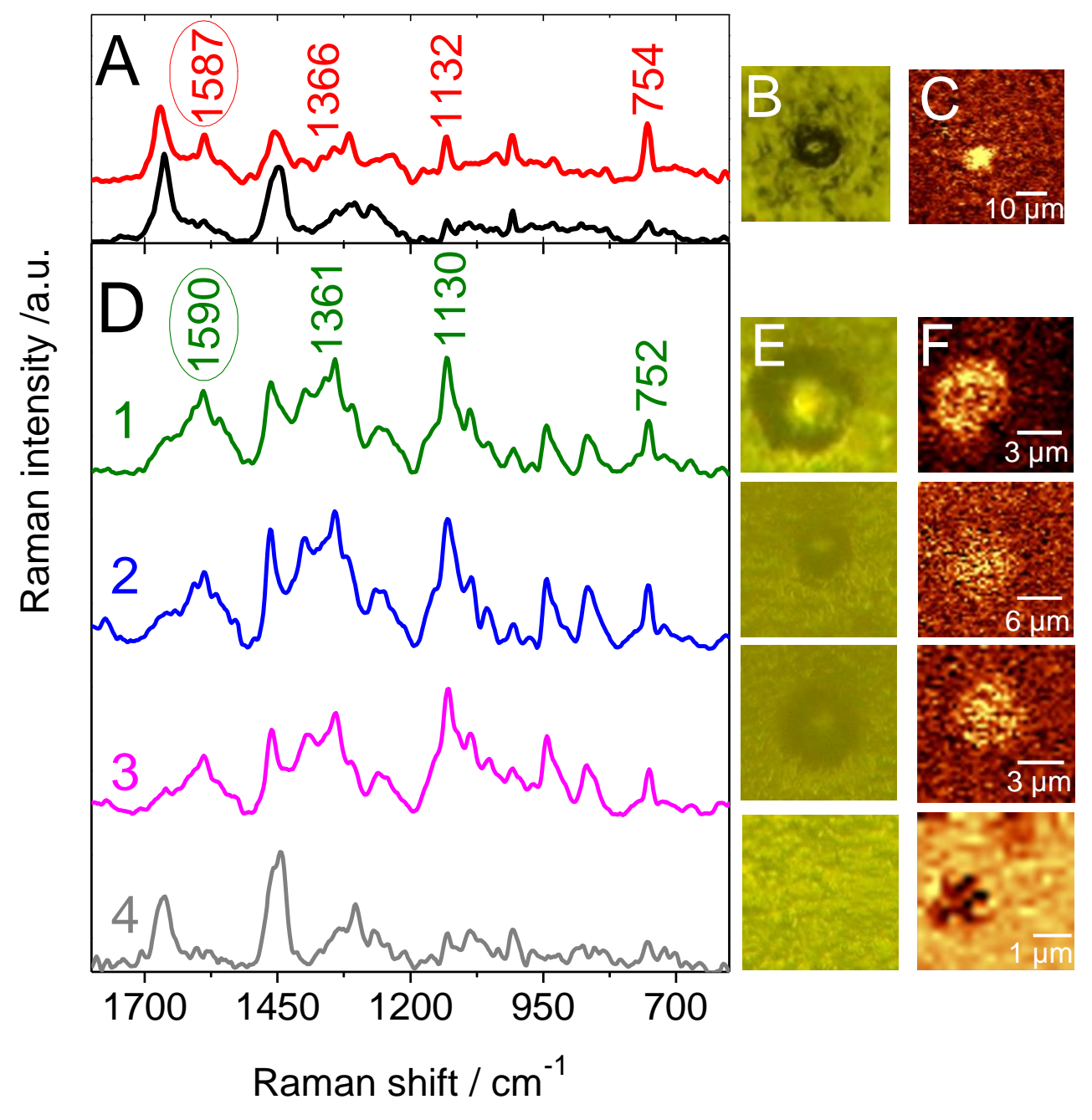

ACS Paragon Plus Environment 


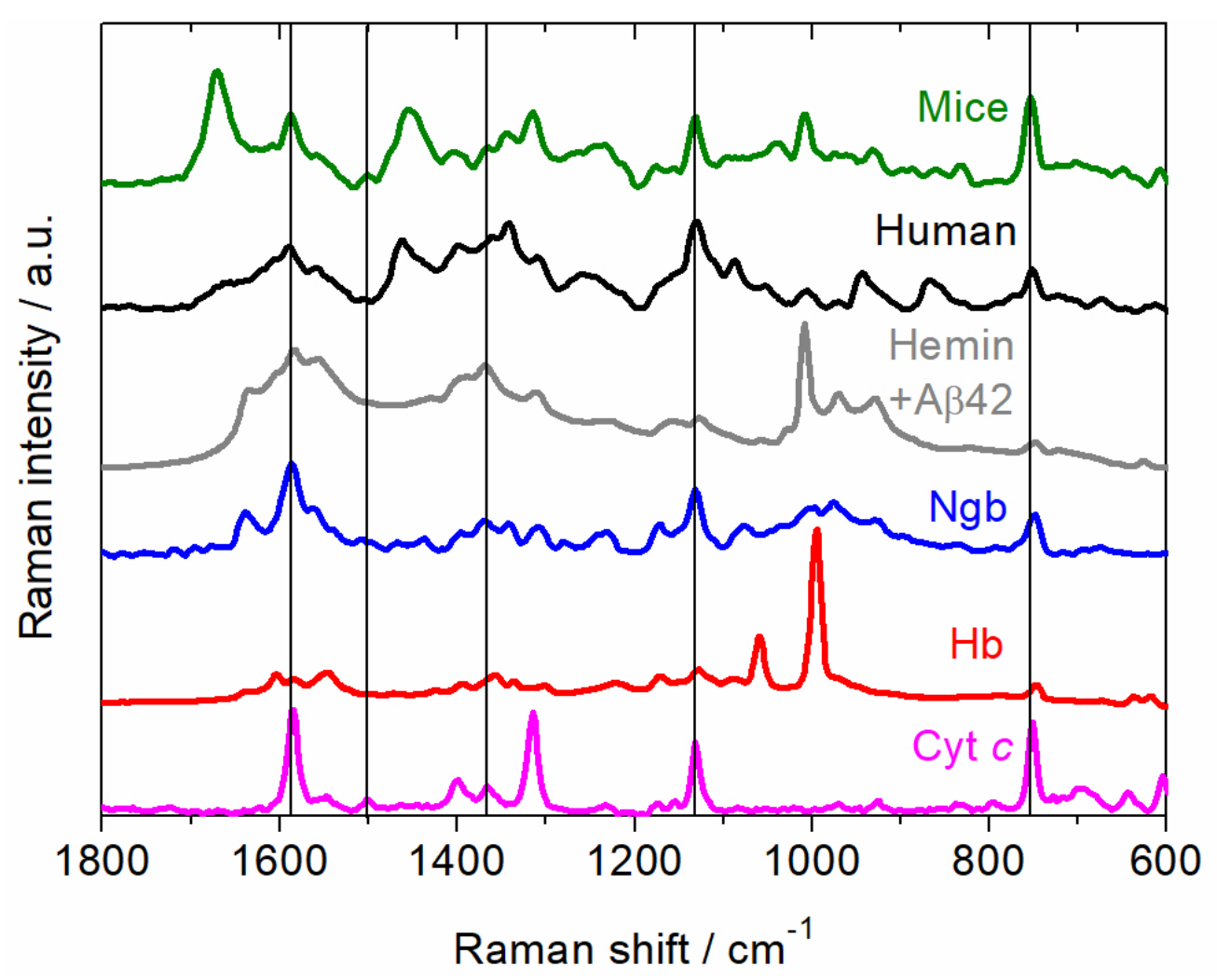

Figure 3

$82 \times 65 \mathrm{~mm}(300 \times 300$ DPI $)$ 